\title{
A PECUÁRIA EXTENSIVA EM GOIÁS: A TÉCNICA NO ESPAÇO RURAL E O CRESCIMENTO HORIZONTAL DA BOVINOCULTURA ENTRE 1920 E $1960^{1}$
}

\author{
EXTENSIVE CATTLE-RAISING IN THE STATE OF GOIÁS: THE TECHNIQUE \\ IN RURAL SPACE AND THE HORIZONTAL GROWTH OF THE CATTLE FARMS \\ FROM 1920 TO 1960
}

\section{LA GANADERÍA EXTENSIVA EN GOIÁS: LA TÉCNICA EN EL ESPACIO RURAL Y EL CRECIMIENTO HORIZONTAL DE LA PRODUCCIÓN TRADICIONAL DE GANADO ENTRE 1920 Y 1960}

\author{
Onofre Aurélio Neto - Fundação Antares de Ensino Superior, Pós-Graduação, \\ Pesquisa e Extensão - Goiânia - Goiás - Brasil \\ opan.neto@yahoo.com.br
}

\begin{abstract}
Resumo
Este artigo discute as inovações técnicas e o uso do espaço rural em Goiás entre 1920 e 1960, com ênfase à pecuária bovina. Apesar de constatarmos uma baixa densidade técnica para o estado, em alguns municípios foi registrada a presença de objetos artificiais, como máquinas e instrumentos agrários; algumas inovações biológicas foram constatadas na alteração do padrão-espécie bovina e na formação de pastagens artificiais; as inovações químicas, apesar de pouco expressivas, marcaram presença, com 0 uso de adubos químicos e 0 processo de calagem. Restritas aos "locais privilegiados", as inovações representam uma modernização heterogênea na fase da bovinocultura tradicional. Na maior parte do território goiano, o problema da escassez de técnicas e da baixa produção espacial foi mitigado com a expansão das áreas de pastagens para sustentar 0 aumento do rebanho, um crescimento horizontal que reforçou a concentração de terra.
\end{abstract}

Palavras-chave: técnica, produção espacial, rebanho bovino, concentração de terra.

\section{Abstract}

This article discusses technical innovations and use of the rural space in Goiás between 1920 and 1960, with attention to the cattle-raising. Despite the fact that Goiás presented the low technique density, some municipalities register the presence of artificial objects, such as machines and agrarian instruments; some biological innovations were evidenced in the alteration of the bovine standard-species and in the formation of artificial pastures; the chemical innovations, although little expressive, mark presence with the use of chemical fertilizers and liming. Restrict to the "privileged places", the innovations represent a functional change in the phase of the traditional cattle farming. In most places, the problem the shortage of techniques and the low spatial production were mitigated with the expansion of the areas of pastures to support the increase of the cattle, a horizontal growth that reinforced the land concentration.

Key words: technique, spatial production, cattle herd, land concentration.

\section{Resumen}

El artículo discute las innovaciones técnicas y el uso del espacio rural en Goiás, entre 1920 y 1960, enfocando en la pecuaria bovina. Aunque evidenciamos baja densidad de técnica en lo estado, algunos municipios registraron la presencia de objetos artificiales, tales como máquinas e instrumentos agrarios; algunas innovaciones biológicas fueron constatadas en la alteración del padrón-especie bovino y en la formación de pastos artificiales; las 
innovaciones químicas, aunque de poca expresividad, estuvieron presentes con el uso de fertilizantes químicos y el proceso de encalar. Limitado a los "lugares privilegiados", las innovaciones representan una modernización heterogénea en la fase de la producción tradicional de ganado. En la mayor parte del territorio goiano, el problema de la escasez de técnicas y baja producción espacial fueron mitigados con la expansión de las áreas de pastoreo para mantener el aumento del rebaño, un crecimiento horizontal que reforzó la concentración de tierra.

Palabras clave: técnica, producción espacial, rebaño bovino, concentración de tierra.

Introdução

Em decorrência de condições naturais e de fatores econômicos e culturais, Valverde (1985) explica que foram desenvolvidos diferentes sistemas de criação de bovinos no Brasil, classificados de forma evolutiva quanto às técnicas utilizadas na produção rural. Em Goiás, até meados do século 20, conforme Gomes e Teixeira Neto (1993), as técnicas utilizadas na criação de gado eram precárias e com baixa capacidade de produção, de maneira que o sistema de criação predominante era a pecuária extensiva.

Andrade (1982) aponta dois problemas da escassez de técnicas na pecuária extensiva: o desgaste do solo e a dificuldade de sustentar o crescimento do rebanho. Nesse último caso, o produtor rural tem optado pela abertura de novas áreas para pastoreio. Assim, a expansão da pecuária contribui para a concentração de terra, pois o aumento do rebanho está ligado à ampliação das áreas de pastagem.

Com base no sistema de criação bovina que prevaleceu na primeira metade do século 20 em Goiás, discutimos neste artigo a questão da densidade técnica, da produção espacial e da concentração de terra entre 1920 e 1960. A pesquisa, realizada em 2013, está fundamentada em revisão bibliográfica e dados censitários do Instituto Brasileiro de Geografia e Estatística (IBGE) para os anos de 1920, 1940 e 1960.

Utilizamos a noção de "densidade técnica" de Santos (2004), quando nos referimos aos objetos artificiais empregados na produção. Para tanto, seguimos a linha de estudo da modernização do campo de Graziano da Silva (1980), classificando as inovações técnicas em biológicas, mecânicas e físico-químicas. Assim, abordamos o melhoramento genético do rebanho, as espécies forrageiras, a formação de pastagem artificial, o emprego de maquinários/instrumentos agrários e a utilização de insumos químicos no espaço rural. A produtividade foi dada pela taxa de lotação (cab./ha). 
A atividade pastoril e o uso do espaço rural no início do século 20

Na primeira metade do século 20, a pecuária bovina destacava-se entre as atividades econômicas desempenhadas no território goiano. $\mathrm{O}$ rebanho bovino, além de ser um produto que se autotransporta e de requerer poucos braços na sua lida, dispunha de uma variedade de capins e forrageiras nos campos do Brasil Central, o que facilitava a prática da atividade. Entre as plantas que brotavam naturalmente no solo goiano e serviam para a alimentação do gado, o pecuarista dispunha dos capins "flexa”, “de raiz”, “mimoso", “da lanceta”, "papuan” e "jequirana”, entre outros, como atesta Henrique Silva (1924).

Apesar das variedades nativas, alguns produtores rurais preferiam formar área de pastoreio com o "capim Jaraguá” ou com o "capim gordura” (catingueiro). Mas, na formação de pastagem com essas variedades, poucos produtores podiam contar com o uso de equipamentos e maquinários mais elaborados, pois, no início do século 20, a enxada, o machado e a foice eram as principais ferramentas usadas no meio rural.

Em Goiás, havia poucas inovações técnicas ao alcance dos produtores rurais nas primeiras décadas do século 20. Segundo Bacha (2012), a pesquisa agropecuária, além de estar restrita a alguns estados, era dominada por duas instituições de São Paulo: o Instituto Agronômico de Campinas (IAC), criado em 1901, e o Instituto Biológico, criado em 1927. A pesquisa agropecuária também se destacava em Minas Gerais, desenvolvida na Escola Superior de Agricultura e Veterinária, inaugurada em 1926 em Viçosa.

Em 1920, Goiás dispunha do menor número de máquinas e instrumentos agrários destinados à exploração da terra entre os estados brasileiros. Apenas em 16 dos 49 municípios que existiam à época eram utilizados esses objetos artificiais, entre os quais um único trator, de um proprietário rural de Catalão. Esse município era um dos três que dispunham de modal ferroviário, por onde chegava parte dos produtos importados.

Além de serem poucos os instrumentos agrários existentes nos municípios goianos, esses objetos estavam concentrados na porção centro-sul. O arado era o instrumento agrário em maior quantidade, com 32 unidades distribuídas em 13 municípios. Ipameri, por exemplo, concentrava 26,6\% dos maquinários existentes em Goiás e era o município com o maior número de grades, arados, semeadeiras, cultivadores, e o único a ter 
um ceifador (IBGE, 1927). Esse cenário revela a baixa densidade técnica do espaço rural goiano, em relação às inovações mecânicas, no início do século 20. A falta de maquinários e instrumentos agrários era ainda mais acentuada em municípios do norte, atual estado do Tocantins.

Com a precariedade das técnicas de produção, fatores naturais e geográficos, como a fertilidade do solo, o regime de chuva, a vegetação e a proximidade do mercado consumidor, entre outros, desempenhavam um papel importante, e por vezes restritivo, na produção espacial. Apesar disso, era expressiva a quantidade de bovinos existentes no estado. Em 1920, Goiás detinha o terceiro maior rebanho bovino do país, com 2.841.081 cabeças, o que representava $8,9 \%$ do plantel nacional.

Entre as raças bovinas criadas em território goiano, de acordo com Silva (1920, p. 93), destacavam-se a Curraleira, o Caracu, a Franqueira, a Pedreira ou Junqueira, o China e o Mocho. Toda essa variedade de gado bovino constituiu, em território nacional, o chamado "gado nativo", espécies rústicas já adaptadas às condições naturais do ambiente. ${ }^{2}$ Em menor quantidade, existiam ainda os exemplares europeus (Bos taurus taurus) da raça Hereford e Holandesa.

Apesar de o "gado nativo" ser a preferência dos criadores em Goiás, nas primeiras décadas do século 20 as fazendas goianas começaram a criar o Zebu (Bos taurus indicus) e a promover o cruzamento deste com o "gado nativo", como indica Silva (1920). A inserção do Zebu ocorreu mais por imposição dos boiadeiros, que davam preferência para a compra desses animais, do que de um anseio dos pecuaristas goianos de alterar o padrão genético de seu rebanho com a raça provinda da Ásia. Para adentrar o território goiano, esses bovinos vinham do Triângulo Mineiro, mais especificamente de Uberaba, que se tornou o "o principal centro de difusão das raças zebuínas no Brasil”, conforme afirma Pereira (2012, p. 16). Em alguns casos, o gado foi importado diretamente da Índia.

Na composição do rebanho goiano de 1920, vacas e novilhas somavam 1.579.047 reses; garrotes e bezerros, 665.881; e bois, 578.153 (IBGE, 1923). Os dados confirmam que Goiás, nas primeiras décadas do século 20, era um estado criador de gado, e não de finalização, com baixo percentual de bois na fase de acabamento e maior percentual de vacas e novilhas, que garantiam os bezerros para a fase de cria.

A região sul destacava-se na produção de gado, especificamente os municípios de Jataí, Rio Verde, Pouso Alto e Catalão, estando os dois 
primeiros entre os 20 municípios com os maiores rebanhos do país em 1920. No norte, o destaque era Boa Vista do Tocantins e Pedro Afonso. Conforme mostra a Figura 1 a seguir, em todos eles predominava um número maior de vacas e novilhas na composição dos rebanhos, seguindo a tendência estadual.

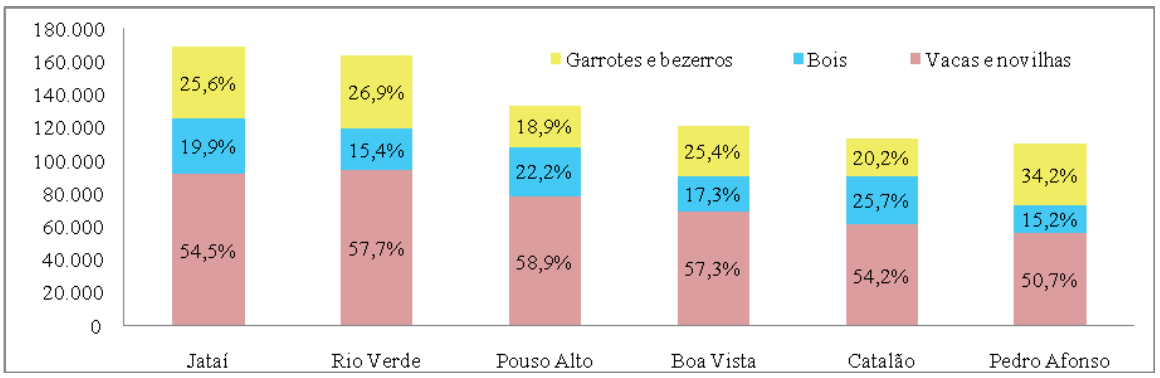

Figura 1 - Municípios goianos com maior rebanho bovino e composição do rebanho em 1920 Fonte: IBGE (1923).

No sudoeste goiano, Jataí, com 178.720 reses, e Rio Verde, com um rebanho de 174.800 cabeças, eram os centros exportadores de gado para esses mercados, utilizando as estradas de rodagens e as comitivas nas estradas boiadeiras, tendo o gado de atravessar rios e percorrer longas distâncias em pé. Com um plantel de 141.967 cabeças, Pouso Alto destinava bovinos para serem abatidos em São Paulo.

No sudeste goiano, onde se localizava a Estrada de Ferro de Goiás, o gado podia ser exportado nos vagões da ferrovia, porém a quantidade deles era insuficiente para a demanda. Catalão, com 121.569 cabeças de gado, desfrutava das poucas estações ferroviárias que existiam no estado, utilizando os vagões para exportar parte do gado e do charque que comercializava com Minas Gerais e São Paulo.

No norte goiano, os produtores comercializavam suas reses com os estados do Pará, Maranhão, Piauí e Bahia, e, para tanto, utilizavam os serviços dos tropeiros e boiadeiros para conduzir os rebanhos (Silva, 1923). Boa Vista do Tocantins, com 129.950 cabeças, e Pedro Afonso, com 117.873 reses, estavam nesse circuito comercial.

Os 16.634 estabelecimentos rurais que existiam em Goiás em 1920 estavam distribuídos em 24.828.210 hectares, de forma que a área média 
das propriedades era de 1.493 ha, o que evidencia a concentração de terra nas mãos de poucos proprietários. As propriedades com até 100 hectares correspondiam a $31,2 \%$ do total de estabelecimentos rurais recenseados, com 5.187 estabelecimentos. As propriedades médias constituíam o maior grupo, com 7.271 estabelecimentos (43,7\%), conforme dados do IBGE (1923). As pequenas propriedades detinham apenas 0,9\% das terras, enquanto as médias agrupavam $12 \%$ e as grandes propriedades, $87,1 \%$ das terras.

A ocupação de terras devolutas e a compra de terras por baixo custo favoreceram o processo de concentração de terra, conforme Borges (2008), reafirmando a estrutura fundiária excludente. Para esse autor, "a criação do gado vacum garantia ao fazendeiro e ao grileiro de terras a apropriação de grandes áreas que se transformavam em reserva de valor" (p. 13). Com isso, formavam-se os latifúndios, as grandes "fazendas de gado", que nem sempre tinham tantos gados assim.

A baixa densidade técnica forçava a um crescimento horizontal da pecuária, ou seja, a um aumento do rebanho, acompanhado pela expansão das áreas de pastagens. Segundo Porto (2004), para amenizar o problema do uso de técnicas tradicionais pouco eficientes, em 1932 foi criado em Urutaí o primeiro local destinado à pesquisa animal em Goiás, com experimentação e monta, tratando-se de uma "fazenda modelo". Localizada na região sudeste, a fazenda estava próxima do Triângulo Mineiro, de onde importava exemplares bovinos para seleção de animais.

\section{Densidade técnica e expansão das fazendas de gado}

Em 1940, segundo o IBGE, existiam 55.908 estabelecimentos rurais em Goiás, dos quais apenas 13\% não praticavam a atividade pecuária, dedicando-se exclusivamente à agricultura. Os estabelecimentos rurais ocupavam uma área de 19.603.521 hectares, dos quais 70,6\% foram declarados como área de pastagem. Os locais que se dedicavam somente à pecuária ocupavam $47,1 \%$ da área total dos estabelecimentos, com 9.653 .344 hectares, enquanto aqueles que tinham como modalidade a agropecuária (lavoura-pecuária) detinham $49,2 \%$, e os que se dedicavam exclusivamente à agricultura, 3,1\% (IBGE, 1952).

Do total de estabelecimentos rurais, somente 30 declararam usar algum tipo de adubo, sendo o de origem vegetal (adubo verde) o mais empregado (76,7\%). Apenas três estabelecimentos declararam utilizar 
adubo mineral, pois a principal forma de reposição dos nutrientes do solo continuava sendo a matéria orgânica. Znamenskiy (1966) pontua que os produtores utilizavam principalmente a casca de arroz misturada com excrementos de animais para repor nutrientes do solo.

De acordo com Waibel (1950), o problema da falta de adubação era recorrente em todo o país, pois o fato de existir terra barata e em abundância fazia com que os produtores rurais se acomodassem e não investissem em fertilizantes. Como resultado da falta de insumos agrícolas, durante viagem ao estado de Goiás entre 1946-1948, Faissol (1952) observou a substituição de áreas de lavoura em "terras cansadas" por campos de pastagem. Segundo ele, essa alteração no uso do espaço rural era decorrente da exploração do solo sem que houvesse reposição dos nutrientes, o que levava a um esgotamento da fertilidade natural após o quinto ano de colheita.

A opção pela pecuária, conforme Faissol (1952, p. 95), só seria viável se o agricultor dispusesse de "uma propriedade de área relativamente grande, pois a criação do gado ainda se faz extensivamente e as pequenas propriedades não teriam capacidade para sustentar um número razoável de cabeças de gado". O relato demonstra como a falta de insumos químicos acarretava a substituição de cultura agrícola por áreas de pastoreio, em casos em que havia "empobrecimento do solo". Nesse sentido, o fator natural, a fertilidade do solo, evidencia uma separação de áreas para agricultura e pecuária.

Em relação aos instrumentos e maquinários utilizados no campo em 1940, os produtores que se dedicavam tanto à lavoura como à criação de animais (modalidade agropecuária) faziam mais uso desses equipamentos do que de outras modalidades de exploração. Considerando todos os tipos de máquinas e instrumentos agrários, a agropecuária detinha 47,6\% dos 936 objetos declarados, conforme mostra a Tabela 1.

$\mathrm{Na}$ atividade pecuária, empregavam-se 340 máquinas e instrumentos agrários ao todo, o que significava $36,3 \%$ dos equipamentos recenseados em 1940. A ocorrência dos objetos artificiais foi maior em estabelecimentos rurais do sudeste, onde contribuíram para a formação de campos de invernada, próximos das charqueadas. Os municípios dessa região apresentaram um elevado percentual de áreas declaradas como de pastagem, ficando acima de 73\%, conforme será visto mais adiante na Figura 2. Entre os instrumentos agrários presentes no espaço rural de Goiás, o arado continuava sendo predominante, com 345 unidades distribuídas 
em 20 municípios. Catalão, Anápolis e Corumbaíba registraram os maiores número de arados, com, respectivamente, 50, 43 e 40 unidades.

Tabela 1 - Máquinas e instrumentos agrários em Goiás, por modalidade de exploração, ano de 1940

\begin{tabular}{|l|r|r|r|r|r|r|r|r|}
\hline \multirow{2}{*}{$\begin{array}{l}\text { Modalidade de } \\
\text { exploração }\end{array}$} & \multicolumn{7}{|c|}{ Máquinas e instrumentos agrários } \\
\cline { 2 - 9 } & Trator & Arado & Grade & Rolo & Semeadeira & Cultivador & Ceifadeira & Pulverizador \\
\hline Agricultura & 1 & 52 & 20 & 9 & 31 & 20 & 1 & 16 \\
\hline Agropecuária & 9 & 159 & 53 & 42 & 96 & 37 & 32 & 18 \\
\hline Pecuária & 3 & 134 & 40 & 37 & 65 & 31 & 13 & 17 \\
\hline TOTAL & 13 & 345 & 113 & 88 & 192 & 88 & 46 & 51 \\
\hline
\end{tabular}

Fonte: IBGE (1952).

Destacamos, entre esses objetos, o uso das grades, que serviram para uma "renovação das pastagens", introduzindo novas espécies em substituição ao campo nativo. Silveira (1997), ao avaliar a importância da grade, expõe que o uso desse equipamento está relacionado às seguintes condições: "Quando a pastagem segue uma cultura anual; em campos com cobertura natural que nunca tenham sido trabalhados; em pastagens cultivadas já estabelecidas sobre as quais se queira sobre semear outra espécie" (p. 16). A partir desse autor, constamos que a "gradeação" representou um avanço técnico para o período, com melhoramento do campo nativo com o cultivo de forrageiras mais nutritivas.

Os estabelecimentos rurais que dispunham de grades estavam distribuídos em apenas 14 municípios. Quatro deles concentravam 63,7\% do total de grades existentes no estado: Catalão e Goiandira possuíam o maior número delas, com 21 unidades em cada um, seguindo-se Corumbaíba com 17, e Anápolis com 13. Apesar de sua utilidade, o trator era pouco empregado no estado, onde havia apenas 13 unidades. Esse baixo número deve-se ao seu custo de aquisição/manutenção e à necessidade de mão de obra para operá-lo, lembrando que o Brasil iniciou a produção de tratores somente na década de 1960.

A Figura 2 leva-nos a afirmar que já existiam inovações/objetos artificiais na década de 1940. Apesar de predominar a pecuária extensiva, alguns produtores rurais utilizavam recursos técnicos, mas essa tecnicização do espaço rural não foi igual em todo o território goiano. Alguns 


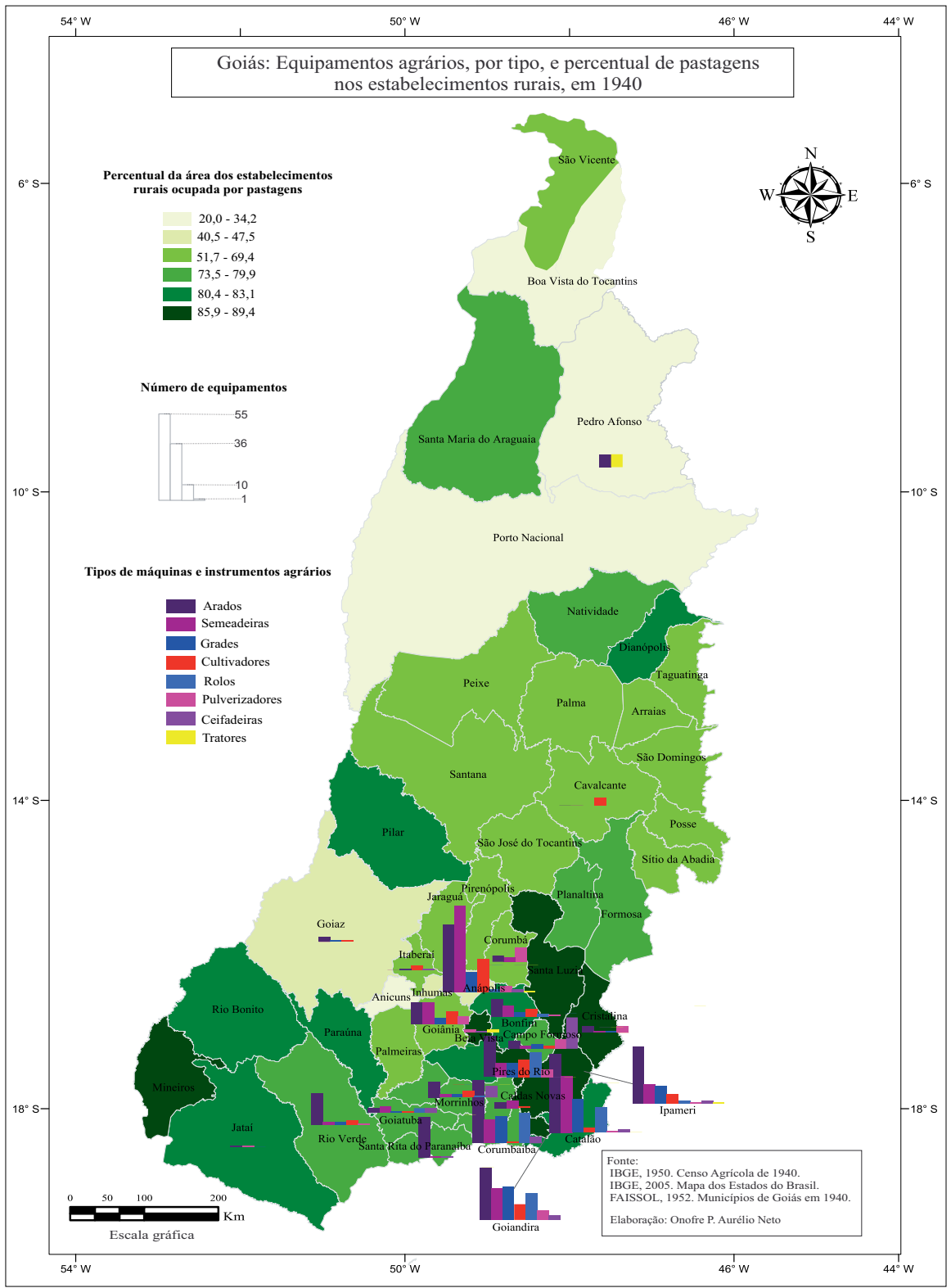

Figura 2 - Mapa dos equipamentos agrários e percentual de área dos estabelecimentos rurais declarada como de pastagem no ano de 1940 
lugares “privilegiados” já dispunham de maquinários e instrumentos agrários desconhecidos pela maioria dos produtores, considerando-se que parte significativa dos municípios não registrou a presença desses objetos. Na pecuária, o uso desses equipamentos favoreceu o processo de expansão das áreas de pastagens, substituindo a vegetação nativa por gramíneas e forrageiras, contribuindo para um crescimento horizontal das áreas de criação bovina.

Entre 1920 e 1940, o rebanho bovino goiano aumentou 4,7\%. Com um efetivo de 2.975.305 cabeças, Goiás detinha 8,7\% da pecuária nacional em 1940. O número de vacas no plantel goiano era de 1.176 .301 cabeças, o que corresponde a 39\% da composição do rebanho; na sequência apareciam os garrotes e novilhas, com 977.786 exemplares; bezerros e bezerras, com 622.002 cabeças; bois de trabalho, com 137.956; e touros reprodutores, com 61.260 exemplares (IBGE, 1950).

Entre as raças criadas em Goiás, de acordo com Fretz (1935), havia as indianas (Gir e Guzerá); as azebuadas, com destaque para o Indubrasil; as europeias; e as nativas ("nacionais"), principalmente a variedade Curraleira. A inserção do Zebu em território goiano, conforme Monserrat e Gonçalves (1954), continuou a ser favorecida pelo empenho do estado mineiro em difundir a raça.

Em 1940, os municípios com maiores efetivos bovinos, conforme podemos visualizar na Figura 3, estavam localizados no extremo norte de Goiás (atual estado do Tocantins), que possuía a maior extensão territorial. O município de Pedro Afonso, com um plantel de 156.449 cabeças, detinha 5,26\% do rebanho goiano, seguindo-se Santa Maria do Araguaia e Boa Vista com 4,74\% e 4,66\% dos bovinos, respectivamente. Esses três municípios do norte somavam 436.288 cabeças. Nesses locais, a matança para suprir o mercado da Região Sudeste do país era menor do que nos municípios do centro-sul.

No sul, especificamente no sudoeste goiano, o destaque continuava sendo para os municípios de Rio Verde, com 136.083 bovinos, e Jataí, com 124.681 bovinos, que representavam 4,57\% e 4,19\% do plantel estadual, respectivamente. Ainda no sudoeste, destacava-se na pecuária o município de Rio Bonito, com 102.675 cabeças (3,5\%). Fora dessa zona, Goiânia, a nova capital estadual, registrava um efetivo de 91.672 bovinos, o que correspondia a $3,08 \%$ do rebanho goiano. Esses sete municípios com os maiores rebanhos bovinos do estado detinham 30\% do plantel, e, em sua composição, o número de vacas era superior a $38 \%$. 


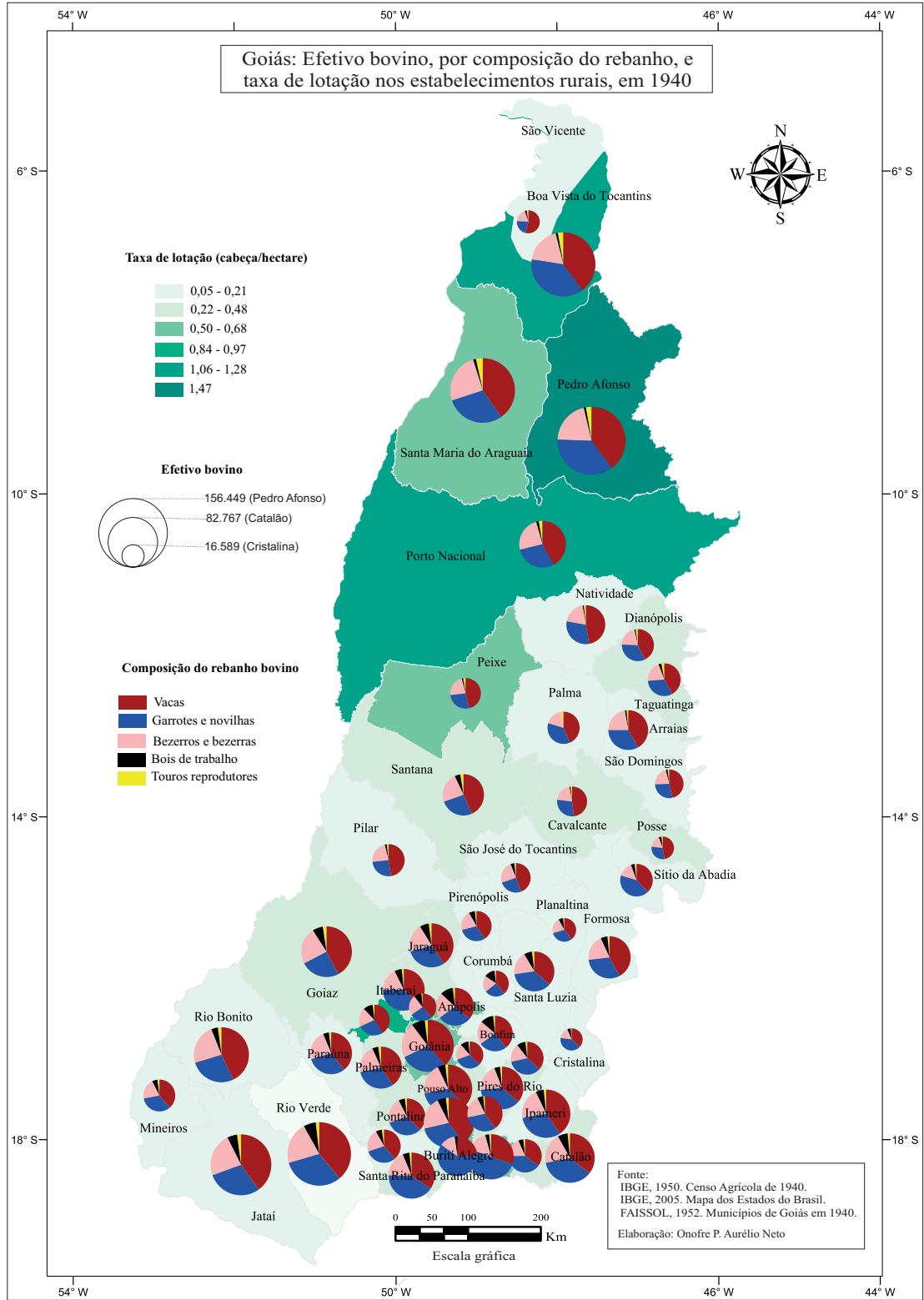

Figura 3 - Mapa do efetivo bovino por composição do rebanho e taxa de lotação nos municípios goianos no ano de 1940

Fonte: IBGE (1950). 
A taxa de lotação para o estado foi de 0,21 cabeça/ha, o que significa que, em média, utilizavam-se cinco hectares de pastagens para cada cabeça de gado. A Figura 3 revela que essa não era a realidade em todo o território goiano, pois alguns municípios registraram uma taxa de lotação maior que 1, caso de Pedro Afonso, com uma taxa de lotação de 1,47; Porto Nacional, com 1,28; Boa Vista, com 1,21; e Buriti Alegre, com 1,06.

Em 41 dos 53 municípios que compunham o território goiano no ano de 1940, constatamos uma taxa de lotação menor do que 0,5 (cab./ha). As menores taxas de lotação foram registradas nos municípios de Cristalina $(0,05)$, Pilar $(0,06)$, Mineiros $(0,07)$ e Jataí $(0,08)$. Com o quarto maior rebanho bovino do estado, Rio Verde tinha uma baixa taxa de lotação, 0,12 (cab./ha), o que demonstra que o gado era criado em grandes fazendas.

A expansão das fazendas de gado refletiu no uso do espaço rural. Em 1940, a área de pastagem correspondia a 70,6\% da extensão dos estabelecimentos, e em 46 dos 53 municípios as áreas de pastagens eram superiores a 51\% do total de hectares recenseados pelo IBGE (1952). Os municípios que registraram maior uso do espaço rural com pastagem foram Santa Luzia, Ipameri, Mineiros, Goiandira e Cristalina, nos quais mais de $87 \%$ das áreas foram declaradas como de pastagem.

Em apenas sete municípios o uso do espaço rural com pastagem foi menor de 50\%. Em Boa Vista, apenas 20\% das áreas foram declaradas com pastagem; em Porto Nacional, 25\%; Pedro Afonso, 34,1\%; Anicuns, 34,2\%; Inhumas, 40,5\%; Anápolis, 46,2\%; e a antiga capital estadual, Goiás, com 47,5\%. No município de Goiânia, a área total dos estabelecimentos rurais era de 304.252 hectares, dos quais 169.382 ha $(55,7 \%)$ foram declarados com pastagem.

Tabela 2 - Estabelecimentos rurais por dimensão territorial e área média em hectares no ano de 1940

\begin{tabular}{|l|c|c|c|c|c|}
\hline \multicolumn{1}{|c|}{$\begin{array}{c}\text { Dimensão dos estabelecimentos } \\
\text { rurais }\end{array}$} & Número & $\%$ & $\begin{array}{c}\text { Área } \\
\text { (hectares) }\end{array}$ & $\%$ & Área média \\
\hline Pequeno (até 100 hectares) & 30.311 & 54,2 & 786083 & 4,0 & 25,9 \\
\hline Médio (+100 até 1.000 hectares) & 20.874 & 37,3 & 6326387 & 32,3 & 303,1 \\
\hline Grande (acima de 1.000 hectares) & 4.617 & 8,3 & 12491051 & 63,7 & $2.705,4$ \\
\hline GOIÁs & 55.908 & 100,0 & 19.603 .521 & 100,0 & 350,6 \\
\hline
\end{tabular}

Fonte: IBGE (1950). 
De acordo com o censo de 1940, a área média dos estabelecimentos rurais goianos era de 350,6 hectares, indicando uma redução de 4,3 vezes em relação ao ano de 1920, o que é atribuído ao aumento das pequenas propriedades, com a ocupação de novas áreas. Porém, esse estrato possuía apenas 4\% da área rural, com uma média de 25,9 hectares.

Os municípios de Jataí, Rio Verde, Boa Vista, Rio Bonito e Natividade - que à exceção deste último, figuravam entre os que possuíam o maior rebanho bovino do estado - registraram o maior número de latifúndios, concentrando um terço das grandes propriedades rurais.

Em Jataí, por exemplo, existiam 416 estabelecimentos acima de mil hectares, o que significava $30,8 \%$ do total das terras destinadas à pecuária no estado, existindo ainda 253 pequenas propriedades e 680 médias propriedades. Em Rio Verde, havia 355 grandes propriedades, com área média de 1.320 ha, e 973 estabelecimentos rurais pequenos.

Existia uma relação direta entre a modalidade de exploração pecuária e o tamanho das propriedades. No decorrer dos anos de 1940, algumas ações tomadas pelo Estado influenciaram no campo e reforçaram essa relação.

A partir da "Marcha para o Oeste", o governo federal promoveu a ocupação e povoamento de "áreas vazias" no Brasil Central, com a criação de colônias agrícolas no país, como é o caso da Colônia Agrícola Nacional de Goiás (CANG), atual município de Ceres. Outra ação do governo federal foi a elaboração de uma legislação fundiária para controlar a venda e distribuição de terras devolutas nas áreas de expansão agrícola. Entretanto, Borges (2008) alerta que o Governo Vargas evitou confrontar-se com o setor agrário, para não perder o apoio deste, e protelou a aplicação da legislação fundiária reformista. Além disso, o poder público não dispunha de controle das terras devolutas. ${ }^{3}$

Durante a administração de Pedro Ludovico Teixeira, os produtores rurais puderam comprar terras devolutas a "preços módicos", como afirmou o próprio interventor em entrevista concedida à Revista Oeste (Teixeira, 1944). Além de facilitar a aquisição dessas terras, os governantes aplicaram outras medidas para aumentar a produção de alimentos. No ano de 1937, o governo federal criou a Carteira de Crédito Agrícola e Industrial (CREAI), com a Lei $\mathrm{n}^{\circ}$ 454, de 9 de julho de 1937, autorizou o Tesouro Nacional a subscrever novas ações do Banco do Brasil e a emitir "bônus" para financiamento da agricultura, pecuária e outras indústrias (Brasil, 1937). 


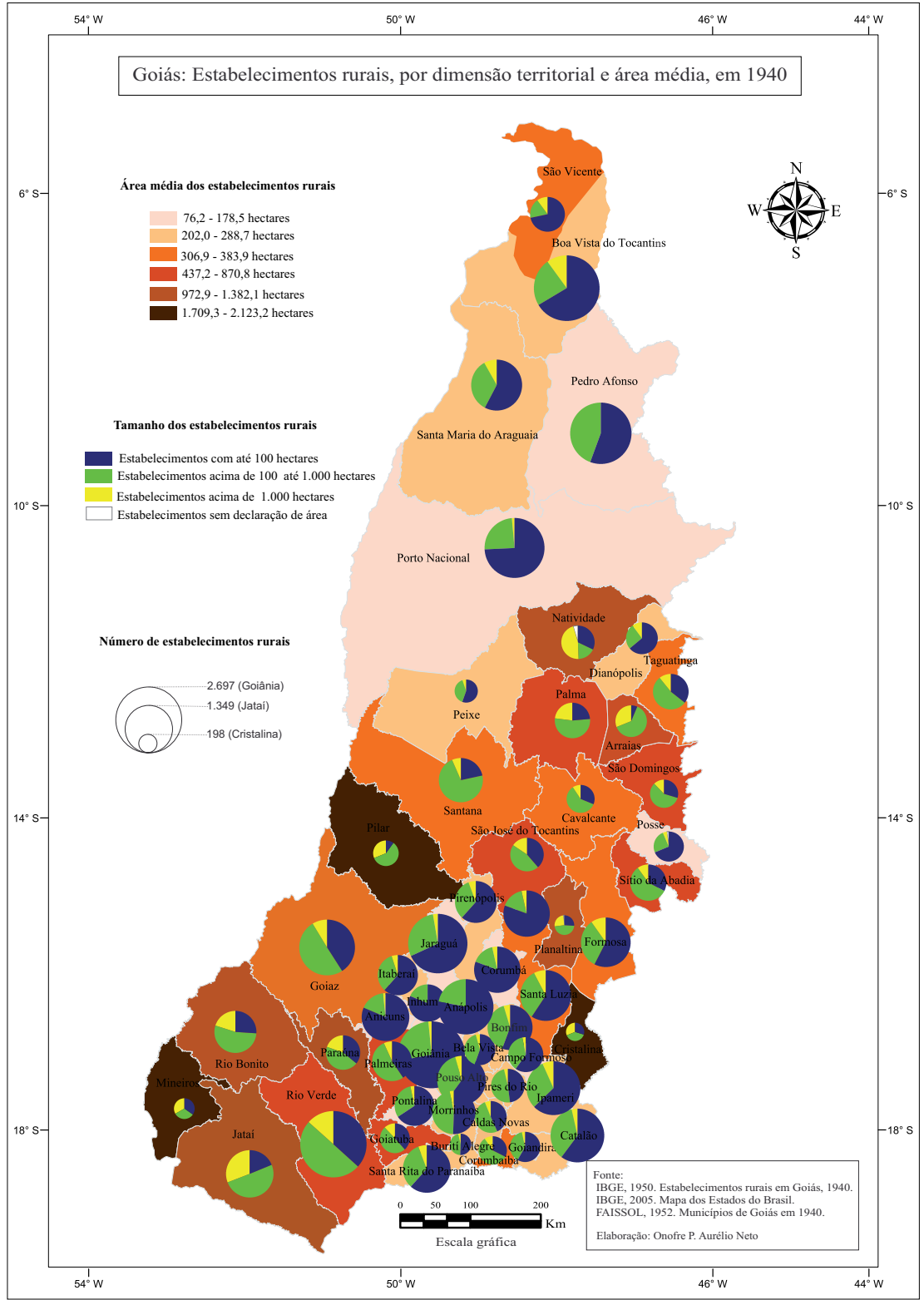

Figura 4 - Mapa dos estabelecimentos rurais por dimensão territorial e área média nos municípios goianos, ano de 1940

Fonte: IBGE (1950). 
Em nível estadual, destaca-se a criação da Sociedade Goiana de Pecuária (SGP) em 1941. Entre as estratégias para desenvolver a produção rural, a SGP deu início à promoção de exposições agropecuárias, a primeira delas realizada em 1942. Durante esses eventos, os organizadores divulgavam exemplares de animais, com o objetivo de padronizar o rebanho em um melhor nível genético, e apresentavam resultados de experimentos agrários para a divulgação de novas práticas no espaço rural, incentivando o uso de adubos químicos, conforme pode ser observado nos trabalhos de Znamenskiy (1966).

0 crédito agrícola e as inovações técnicas no espaço rural

Os subsídios impulsionaram as inovações no campo e contribuíram para o aumento da produção nos locais em que chegaram, uma vez que poucos tiveram acesso a esses créditos. Em 1959, segundo o Censo do IBGE (1970), apenas 4.793 dos 111.015 estabelecimentos rurais que existiam em Goiás receberam algum tipo de financiamento, o que representava 4,3\% do total. Entre os produtores rurais beneficiados, 3.540 receberam crédito de entidades públicas (73,9\%), conforme aponta a Tabela 3.

Tabela 3 - Estabelecimentos rurais que obtiveram financiamento, por fonte de crédito, em 1959

\begin{tabular}{|c|c|c|c|c|c|c|c|}
\hline \multirow{3}{*}{$\begin{array}{l}\text { Dimensão dos } \\
\text { estabelecimentos } \\
\text { que obtiveram } \\
\text { financiamento }\end{array}$} & \multicolumn{7}{|c|}{ Fonte fornecedora de crédito } \\
\hline & \multicolumn{2}{|c|}{ Entidade pública } & \multicolumn{2}{|c|}{ Particulares } & \multirow{2}{*}{$\begin{array}{c}\begin{array}{c}\text { Públicas e } \\
\text { particulares }\end{array} \\
\text { Quantidade }\end{array}$} & \multirow[b]{2}{*}{$(\%)$} & \multirow[t]{2}{*}{ TOTAL } \\
\hline & Quantidade & $(\%)$ & Quantidade & $(\%)$ & & & \\
\hline Até 100 hectares & 1.190 & 63,1 & 596 & 31,6 & 101 & 5,4 & 1.887 \\
\hline $\begin{array}{l}+100 \text { até } 1000 \\
\text { hectares }\end{array}$ & 1.957 & 79,9 & 389 & 15,9 & 103 & 4,2 & 2.449 \\
\hline $\begin{array}{l}\text { Acima de } 1.000 \\
\text { hectares }\end{array}$ & 393 & 86,0 & 47 & 10,3 & 17 & 3,7 & 457 \\
\hline GOIÁS & 3.540 & 73,9 & 1.032 & 21,5 & 221 & 4,6 & 4.793 \\
\hline
\end{tabular}

Fonte: IBGE (1970).

Analisando a distribuição dos créditos conforme o tamanho dos estabelecimentos, as grandes e médias propriedades foram as mais beneficiadas, pois 60,6\% delas tinham mais de 100 hectares. A participação relativa das entidades públicas foi maior nos estabelecimentos rurais acima de mil hectares, enquanto uma em cada três pequenas propriedades que 
receberam financiamento teve de recorrer ao capital privado, aos empréstimos em bancos particulares ou com comerciantes.

Apesar de o acesso ao crédito ter sido restrito a alguns produtores, de uma maneira geral, a política de expansão agrícola refletiu em um aumento do número de estabelecimentos rurais, que passou de $55.908 \mathrm{em}$ 1940, para 111.015 em 1960, variação que representou um acréscimo de 98,6\% das propriedades. Nesse mesmo intervalo, ao observar os principais tipos de uso da terra, constatamos que as áreas de pastagens foram expandidas em 38,5\%, distribuídas em mais de 19 milhões de hectares, enquanto a lavoura teve um aumento de $180,3 \%$ em 1960, ocupando uma área superior a 988 mil hectares.

Segundo o Censo Agrícola do IBGE de 1960, publicado em 1967, pelo menos 499.207 pessoas desempenhavam alguma atividade no espaço rural, pois, com poucos recursos técnicos, o trabalho braçal era fundamental nas atividades agrárias. O tipo de força utilizada no campo ainda era predominantemente a humana, presente em 102.970 estabelecimentos, o que correspondia a $92,8 \%$ do total; em seguida, empregava-se a força animal, usada em 6.910 propriedades $(6,2 \%)$. Em relação ao uso da força mecânica, 481 estabelecimentos declararam utilizá-la, ou seja, 0,4\%; e 654 usavam força mecânica em conjunto com a força animal, 0,6\% (IBGE, 1967).

Ao todo, existiam 1.349 tratores e 6.497 arados nos estabelecimentos rurais em 1960 , dos quais $13,1 \%$ e $56,3 \%$, respectivamente, estavam em propriedades com até 100 hectares. Nesse ano foi também constatada a existência de 4.166 cultivadores, 2.554 semeadeiras, 1.707 grades e 548 pulverizadores e polvilhadeiras no estado. A distribuição espacial dos equipamentos agrários continuava desigual, com maior número de objetos em municípios do centro-sul (Mato Grosso Goiano, sudeste e sudoeste). Considerando a ocorrência de tratores, Itumbiara contava com 337 unidades, Goiatuba com 155, Rio Verde com 135 e Quirinópolis com 68, somando $51,5 \%$ do total estadual desse equipamento.

O Censo Agrícola de 1960 do IBGE (1967) também levantou que somente 923 estabelecimentos utilizavam algum tipo de adubação, sendo a orgânica o principal tipo, com 711 ocorrências. A adubação química era utilizada por 35 estabelecimentos, o que representava apenas $0,03 \%$ do total, e outras 177 propriedades utilizavam ambos os tipos (química e orgânica). Em todas as três categorias de estabelecimentos por dimensão territorial predominava o uso do adubo orgânico, conforme poderá ser visto na Figura 5 a seguir. 


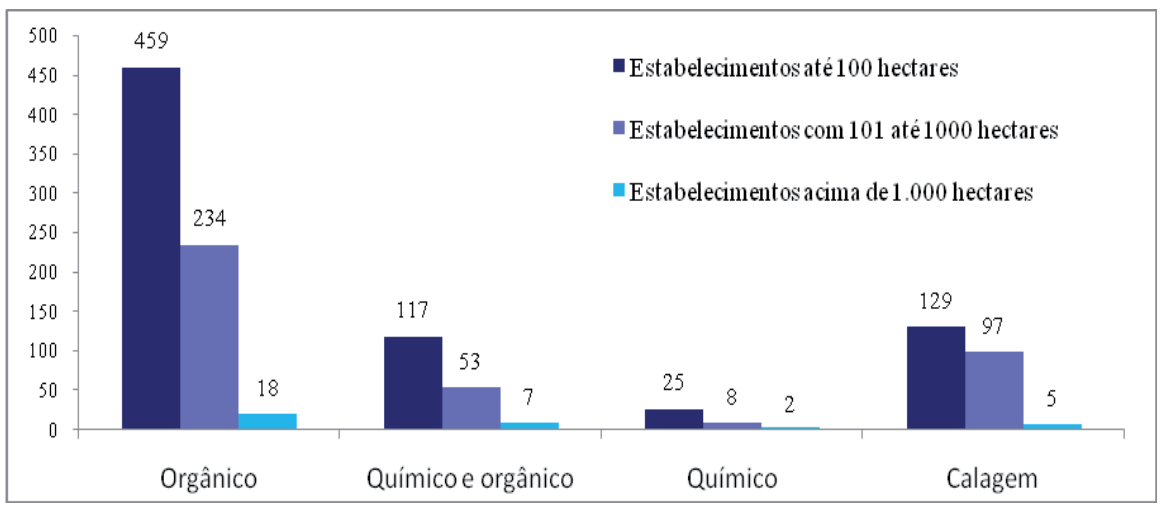

Figura 5 - Estabelecimentos rurais em Goiás que usavam fertilizantes, por dimensão, em 1960 Fonte: IBGE (1970).

A aplicação da cal como corretivo do solo foi registrada em 231 propriedades, das quais 129 eram de extensões pequenas, e representava $55,8 \%$ do total de ocorrências. Mas a cal já era utilizada em alguns estabelecimentos rurais no fim dos anos de 1950 no processo de calagem, que consiste na adição de calcário no solo para reduzir a sua acidez, sendo mais utilizada por estabelecimentos que se dedicavam a culturas temporárias e com dimensão territorial de até 100 hectares.

Do total de estabelecimentos rurais recenseados em 1960, 74.667 declararam possuir pastagens naturais e 50.009, pastagens artificiais. ${ }^{4} \mathrm{O}$ primeiro tipo era ainda predominante e ocupava uma área de 16.060.502 hectares; o segundo abrangia um total de 3.107.592 ha. Ao todo, as pastagens correspondiam a $66,4 \%$ do uso do espaço rural.

Entre as gramíneas forrageiras existentes em Goiás na década de 1950, predominavam o capim Jaraguá (Hyparrhenia rufa) e o capim gordura (Melinisminutiflora), sendo o primeiro, de acordo com Znamenskiy (1966), a espécie mais difundida na parte sul do estado. Em relação às pastagens artificiais, 48,1\% delas estavam em estabelecimentos com dimensão territorial acima de 100 e até 1.000 ha, e 38,8\% em fazendas com mais de mil hectares (IBGE, 1967).

Os municípios com as maiores áreas de pastagens artificiais eram Caiapônia (267.758 ha), Rio Verde (167.741 ha), Quirinópolis (98.426 ha), Palmeiras de Goiás (80.691 ha), Goiatuba (79.711 ha) e Jataí (75.013 ha) (IBGE, 1967). Com exceção de Jataí, que possuía 15\% de pastagens plan- 
tadas e 85\% naturais, em todos esses outros municípios o percentual de pastagens artificiais era maior do que $26 \%$, ou seja, em cada 4 hectares de pastagens, pelo menos um era plantado.

Em 1960, existiam em Goiás 73.920 estabelecimentos dedicados à criação de bovinos, que abrigavam 4.862 .782 reses, o que equivalia a $8,7 \%$ do gado nacional. Considerando a dimensão dos estabelecimentos, notamos que $51 \%$ do total de bovinos, ou seja, 2.481.748 cabeças, estavam em 31.520 estabelecimentos com mais de 100 e até mil hectares. Os 4.999 estabelecimentos acima de mil hectares que se dedicavam à criação de gado detinham $31,8 \%$ do rebanho, enquanto as pequenas propriedades, apesar de ser o grupo em maior número (37.395 estabelecimentos), dispunham de 832.545 bovinos, o que representava 17,1\% do plantel estadual, conforme dados do IBGE (1970).

Os municípios goianos com os maiores efetivos bovinos eram Rio Verde (111.652 cabeças), Catalão (103.406), Caiapônia (98.771), Porto Nacional (97.837) e Cristalândia, com 96.286 (IBGE, 1970). Em conjunto, esses cinco municípios detinham 10,4\% do plantel, o que indica que, apesar de continuarem com um efetivo bovino elevado, houve uma queda, visto que em 1940 eles concentravam 23,4\% de todo o gado do estado. Daí se deduz que diminuiu também o grau de concentração do rebanho em determinados municípios tradicionais, com a criação bovina dispersando-se mais pelo estado.

Essa dispersão do gado bovino justifica-se, em parte, pela disponibilidade de terras e pelo seu baixo custo, principalmente no médio-norte goiano. Como afirma Barreira (1997), a partir de 1950 houve uma expansão da fronteira agrícola nos municípios dessa região, com a incorporação de novas áreas ao setor agropecuário.

Monserrat e Gonçalves (1954, p. 72) constataram que nos anos de 1950 o rebanho bovino estava dividido entre o gado "Curraleiro" (30\%), e o Zebu/azebuado (70\%). Em sua distribuição geográfica, o gado nativo predominava no norte e o Zebu, no centro-sul. Considerado o gado de corte ideal para a região do Brasil Central, o Zebu (Gir, Guzerá, Indubrasil e Tabapuã) ganhava cada vez mais espaço nas fazendas de cria, recria e nas invernadas.

$\mathrm{Na}$ composição do rebanho goiano, as vacas, em um total de 1.732.394 cabeças, representavam 35,6\% do plantel, e as novilhas, 9,6\%. O quantitativo de bezerros e bezerras até dois anos correspondia a $38,1 \%$; 
os bois e garrotes para corte, 551.063 cabeças (11,3\%). Em seguida estavam os bois de trabalho $(3,6 \%)$ e os touros $(1,7 \%)$, que eram destinados à reprodução, com vistas à seleção e melhoramento do rebanho.

A participação relativa das vacas na composição do rebanho diminuiu desde o início do século 20 até a década de 1960. Em 1920, o percentual de vacas e novilhas era de 56\%; em 1940, de 39,5\%; e em 1960, $35,6 \%$, o que significa uma redução percentual de 3,9\%, em vinte anos. Em compensação, aumentava o número de bois e garrotes para corte, engordados no próprio território goiano, o que se deve, em parte, ao aumento dos estabelecimentos rurais que se dedicavam à invernada.

Em 1960, existiam no estado 1.315 estabelecimentos que tinham como atividade principal a invernada/campo de engorda, ocupando uma área total de 318.877 hectares (IBGE, 1967). Inhumas, com 175 invernadas; Goianira, com 144; e Goiânia, com 66, registraram a maior quantidade de fazendas destinadas à engorda do gado, em 1960. Em Inhumas, as invernadas ocupavam uma área de 3.573 hectares, com uma taxa de lotação de 0,71 (cab./ha), acima da média estadual. Em Goianira, a taxa de lotação foi de 0,55 cab./ha, e na capital estadual, de 0,48 cab./ha.

A taxa de lotação em 1960 para o estado foi de 0,25, o que significa que, em média, eram utilizados quatro hectares de pastagens para cada bovino. Podemos dizer que, nesse ano, uma fazenda com 100 bovinos necessitava em média de 400 hectares de pastagens, enquanto vinte anos antes eram necessários 500 hectares para sustentar a mesma quantidade de gado.

Em 1960, dos 111.015 estabelecimentos rurais recenseados, 62,7\% eram pequenas propriedades, que ocupavam uma área de 2.397.177 hectares (8,3\%). As propriedades acima de 100 e até mil hectares somavam a 36.149 estabelecimentos, detendo $41,6 \%$ das terras (12.008.648 ha). Existiam 5.284 propriedades com mais de mil hectares, as quais concentravam 50,1\% das áreas declaradas (14.471.489 ha), conforme dados do IBGE (1967).

A área média dos estabelecimentos rurais em Goiás era de 260,1 hectares. Os municípios com maiores valores de área média foram Aporé (2.713,3 ha), Aragarças (1.833,2 ha), Serranópolis (1.744,9 ha), Cristalina (1.651,9 ha) e Santa Rita do Araguaia (1.435,3 ha). Nesses cinco municípios predominavam as áreas de pastagens na composição do espaço rural. Em Aporé, por exemplo, os estabelecimentos rurais estavam distribuídos em 
uma área de 409.710 hectares, sendo que 341.387 ha eram pastagens naturais e 16.970 ha, pastagens plantadas.

Em 1960, a pecuária bovina era a atividade principal em 32.359 estabelecimentos rurais de Goiás, o que representava 29,2\% do total. Essas propriedades ocupavam 18.421.816 hectares, 67\% da área rural (IBGE, 1967). Se considerarmos apenas os estabelecimentos onde a pecuária bovina era a atividade predominante, o tamanho médio das propriedades no estado sobe para 569,3 ha, um aumento de 2,2 vezes o tamanho médio, independentemente da atividade desenvolvida (260,1 ha).

A maioria das propriedades em que predominava a criação de gado (55\%) tinha uma dimensão entre 100 e mil hectares, ocupando 36,3\% das terras, enquanto os grandes estabelecimentos, acima de mil hectares, concentravam 60,8\% das terras (IBGE, 1967). Esses dados demonstram o efeito da pecuária bovina na concentração de terra em Goiás.

\section{Considerações finais}

Na primeira metade do século 20, a pecuária extensiva predominava em Goiás, demandando grandes áreas de pastagem para sustentar o aumento do rebanho. Houve então um crescimento horizontal de estabelecimentos com essa atividade econômica, processo que reforçou a concentração de terra, visto que contribuiu para a formação de médias e grandes propriedades, com fazendas de gado acima de 100 hectares.

Nas palavras de Borges (2008, p. 100), “a pecuária extensiva tinha 'fome' por terra”. Em parte, isso ocorreu em decorrência da falta de insumos industriais para a pecuária, entre eles, os fertilizantes químicos, que possibilitariam uma maior produção espacial, ou seja, uma maior capacidade de lotação, pois uma maior fertilidade do solo permitiria a formação de melhores pastagens. Nos locais em que ocorreu a formação de pastos com capim Jaraguá, colonião ou gordura em terras mais férteis, registrou-se uma maior capacidade de lotação, ou seja, uma maior produção espacial, no caso dos campos de invernada.

É bem verdade que ainda na primeira metade do século 20 ocorreram algumas modificações nas formas de produzir o rebanho bovino no Brasil, inclusive em Goiás, com a implantação de gramíneas estrangeiras substituindo o capim natural do cerrado, e o cruzamento de raças. Mas a difusão de técnicas que garantissem uma maior produtividade foi restrita 
a alguns espaços, assim como a concessão de crédito agrícola. As inovações técnicas no período não atingiram todo o território goiano, com uma maior ocorrência de objetos artificiais no sudeste e na parte central do estado.

\section{Notas}

1. Este texto origina-se da dissertação de Mestrado do autor, Pecuária goiana: a tecnicização do espaço rural e a internacionalização do agronegócio da carne bovina (1920-2012), 2014, Instituto de Estudos Socioambientais, Universidade Federal de Goiás, sob orientação do professor Dr. Tadeu Alencar Arrais, e financiada pela Coordenação de Aperfeiçoamento de Pessoal de Nível Superior (CAPES).

2. Algumas das "raças nativas do Brasil" já se extinguiram, como afirmam Carvalho et al. (2010, p. 11), como é o caso das raças Pedreira, China e Franqueira; outras variedades, como a Junqueira, o Mocho Nacional e o Pé-Duro, encontram-se em risco de extinção, sendo preservadas pela Embrapa.

3. Uma prova da força do setor agrário foi dada em 1943, durante o II Congresso Pecuário, em Campo Grande. Borges (2008) conta que durante esse evento os líderes rurais opuseram-se ao projeto de legislação fundiária de Vargas, que limitava a compra de terras devolutas em 500 hectares; em vez disso, exigiram um aumento do limite para no mínimo 3.600 ha quando a propriedade se destinasse à criação de gado.

4. Parte dos municípios possuía tanto pastagens naturais quanto artificiais. $\mathrm{O}$ IBGE (1967, p. XVI) define pastagens naturais como "áreas destinadas ao pastoreio do gado, sem terem sido formadas mediante plantio, ainda que tenha recebido algum trato", enquanto as artificiais são as "áreas destinadas ao pastoreio e formadas mediante plantio”.

\section{Referências}

ANDRADE, M. C. de. Áreas de domínio da pecuária extensiva e semi-intensiva na Bahia e norte de Minas Gerais. Recife: Sudene, 1982.

BACHA, C. J. C. Economia e política agrícola no Brasil. 2. ed. São Paulo: Atlas, 2012.

BARREIRA, C. C. M. A. Região da estrada do boi: usos e abusos da natureza. Goiânia: Cegraf, 1997.

BRASIL. Lei $n^{o}$ 454, de 9 de julho de 1937. Autoriza o Tesouro Nacional a subscrever novas ações do Banco do Brasil. Disponível em: <http://www2.camara.leg.br/ legin/fed/lei/1930-1939/lei-454-9-julho-1937-503317-norma-pl.html>. Acesso em: $12 / 01 / 2014$. 
BORGES, B. G. Estado e economia no Brasil Central: o poder dos grandes produtores rurais. Goiânia: Ed. UCG, 2008.

CARVAlHO, G. M. C.; ALMEIDA, M. J. de O.; AZEVÊDO, S. M. M. R.; ARAÚJO NETO, R. B.; LEAL, T. M.; MONTEIRO, F. das C.; FROTA, M. N. L. da; LIMA NETO, A. F. Origem, formação e conservação do gado Pé-Duro, o bovino do Nordeste brasileiro. Teresina: EMBRAPA, 2010.

FAISSOL, S. O Mato Grosso de Goiás. Rio de Janeiro: IBGE, 1952.

FRETZ, W. A necessidade de melhoramento de nossas raças indígenas. $A$ Informação Goyana, v. XIX, n. 6 e 7. Rio de Janeiro, 1935.

GRAZIANO DA SILVA, J. Progresso técnico e relações de trabalho na agricultura paulista. Tese (Doutorado em Economia). Instituto de Economia, Universidade Estadual de Campinas, Campinas, SP, 1980.

GOMES, H.; TEIXEIRA NETO, A. Geografia Goiás-Tocantins. Goiânia: Cegraf, 1993.

IBGE. Censo Agrícola de 1960 - Mato Grosso, Goiás e Distrito Federal. Rio de Janeiro: IBGE, 1967. (Série Regional, v. II, Tomo XIV, $1^{\mathrm{a}}$ parte)

. Censo Agrícola de 1960 - Mato Grosso, Goiás e Distrito Federal. Rio de Janeiro: IBGE, 1970. (Série Regional, v. II, Tomo XIV, $2^{a}$ parte)

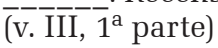

. Recenseamento Geral do Brasil, 1920 - Agricultura. Rio de Janeiro, 1923.

. Recenseamento Geral do Brasil, 1920 - Agricultura. Rio de Janeiro, 1927. (v. IIII, $\overline{3}^{\mathrm{a}}$ parte)

- Recenseamento Geral do Brasil, 1940 - Censo Demográfico e Censos Econômicos. Rio de Janeiro, 1952. (Série Regional, parte XXI, Goiás)

. Recenseamento Geral do Brasil, 1940 - Censos Econômicos: Agrícola, Industrial, Comercial e dos Serviços. Rio de Janeiro, 1950. (v. 3)

MONSERRAT, E. J.; GONÇALVES, C. A. Observações sobre a pecuária no Brasil Central. Porto Alegre (RS): Seção de Informações e Publicidade Agrícola (documento n. 5), 1954.

PEREIRA, M. F. V. As atividades modernas da genética bovina no Brasil: funções e lógicas da especialização em Uberaba (MG). Boletim Goiano de Geografia, Goiânia, v. 32, n. 2, p. 13-32, jul./dez. 2012.

PORTO, M. R. Ministério da Agricultura. In: PEREIRA, A. A. (Org.). Agricultura de Goiás: análise \& dinâmica. Brasília: Ed. UCG, 2004. p. 53-87.

SANTOS, M. A natureza do espaço: técnica e tempo, razão e emoção. São Paulo: Edusp, 2004.

SILVA, H. Cultivemos as nossas forrageiras indígenas. A Informação Goyana, v. VII, n. 12. Rio de Janeiro, 1924.

Janeiro, 1923.

. Goyaz e sua exportação bovina. A Informação Goyana, v. VII, n. 3. Rio de 
Informąção Goyana, v. III, n. 8. Rio de Janeiro, 1920.

SILVEIRA, Gastão Moraes da. Máquinas para a pecuária. São Paulo: Nobel, 1997.

TEIXEIRA, P. L. O Estado de Goiás e as suas imensas possibilidades econômicas: depoimento [Maio de 1944]. Goiânia: Revista Oeste, ano III, n. 16, maio de 1944. Entrevista concedida ao Correio da Manhã.

VALVERDE, O. Estudos de Geografia Agrária Brasileira. Petrópolis, RJ: Vozes, 1985.

WAIBEL, L. O que aprendi no Brasil. Revista Brasileira de Geografia. Rio de Janeiro, ano XII, n. 3, p. 419-428, jul./set. 1950.

ZNAMENSKIY, V. Informações sobre o aproveitamento agropastoril do cerrado de Goiás. Goiânia: CERNE, Secretaria da Agricultura do Estado de Goiás, 1966. 73 p.

Onofre Aurélio Neto - Possui Graduação e Mestrado em Geografia pela Universidade Federal de Goiás. Atualmente é professor na Fundação Antares de Ensino Superior, Pós-Graduação, Pesquisa e Extensão.

Recebido para publicação em 29 de agosto de 2014 Aceito para publicação em 5 de outubro de 2014 